\title{
Crítica al uso de la memoria como recurso de aprendizaje durante el siglo XIX en Chile ${ }^{1}$
}

\author{
Criticism of the use of memory as a learning \\ resource during the 19th century in Chile \\ Críticas ao uso da memória como recurso de \\ aprendizado durante o século XIX no Chile \\ Zugutugen ta azümael pu weke che re logkontukun \\ mew amulechi siglo XIX Chile mew
}

\author{
Jesús Lara Coronado ${ }^{2}$ \\ Universidad Austral de Chile, Chile
}

Recepción: 19/11/2018

Evaluación: 08/05/2019

Aceptación: 23/05/2019

Artículo de Investigación - Revisión

DOI: https://doi.org/10.19053/01227238.9776

\begin{abstract}
RESUMEN
El presente artículo tiene como propósito dilucidar de qué manera, durante gran parte del siglo XIX, en Chile, se comenzó a discutir el tipo de enseñanza que se empleaba en la educación, principalmente la que estaba orientada a desarrollar la transferencia de información de forma mecánica, teniendo como único propósito el desarrollo de la memoria para repetir conceptos y frases. Por esta razón, se realizó un revisionismo historiográfico de fuentes primarias de aquella

cuáles eran las posturas y las críticas que se hacían a las estrategias educativas clericales, pero también cuáles eran las orientaciones pedagógicas que se debían comenzar a adoptar para generar cambios en la educación. En consecuencia, el aporte de este estudio consiste en demostrar que la voluntad de reestructurar la enseñanza-aprendizaje, centrada en el desarrollo de habilidades de orden superior en los estudiantes, tiene antecedentes continuos a lo largo de todo el siglo XIX.
\end{abstract} época, para, por medio de ellas, analizar

1 Este artículo surge bajo el patrocinio del Convento Dominico de Santiago de Chile y el Instituto Dominico de Investigaciones Históricas de Querétaro, instituciones que facilitaron el acceso a sus archivos y financiaron viajes y pasantías para desarrollar la investigación. El proyecto se enmarca dentro de la investigación: "La pedagogía de los frailes dominicos del siglo XVI al XX”, en la cual el autor participó como coordinador del proyecto junto a fray Eugenio Torres, director del Instituto Dominico de Investigaciones Históricas.

2 Doctor en Pedagogía por la Universidad Nacional Autónoma de México, académico de tiempo completo de la Universidad Austral de Chile, sede Puerto Montt, investigador invitado del Instituto Dominico de Investigaciones Históricas. jesus.lara@uach.cl 
Palabras clave: Revista historia de la educación latinoamericana; memoria; aprendizaje; didáctica; modelo; educación.

\section{ABSTRACT}

The purpose of this article is to elucidate how, during much of the 19th century, in Chile, the type of teaching that used to be transmitted began to be discussed, mainly that oriented towards the mechanic transfer of information, having as its sole purpose the development of memory to repeat concepts and phrases. For this reason, we carried out historiographic revisionism of primary sources from that time, in order to analyze the positions and criticisms against the clerical educational strategies, but also, to identify the pedagogical orientations that should begin to be adopted to generate changes in education.

Consequently, the contribution of this study is to demonstrate that the concern for the restructuring of the teaching-learning processes, focused on the development of higher-order skills in students, has an ongoing background throughout the nineteenth century.

Keywords: Journal History of Latin American Education; memory; learning; didactics; model; education

\section{RESUMO}

O presente artigo tem como proposito esclarecer de que maneira, durante grande parte do século XIX no Chile, se começou a discutir o tipo de educação que se usava na educação, principalmente a que estava orientada a desenvolver a transferência de informação de forma mecânica, tendo como única proposta o desenvolvimento da memória para repetir conceitos e frases.

Por esta razão, se realizou uma revisão histórica de fontes primarias da aquela época, para, por meio destas, analisar quais eram as posturas e as críticas que se faziam a as estratégias educativas clericais, mas também, quais eram as orientações pedagógicas que se deviam começar a adotar para gerar mudanças na educação. Como consequência, a contribuição desse estudo e demonstrar que a preocupação pela reestruturação do ensino- aprendizagem, centrada no desenvolvimento de profundas habilidades nos estudantes, tem antecedentes contínuos durante todo o século XIX.

Palavras chaves: revista historia da educação latino-americana; memoria; aprendizado; didatica; modelo; educação.

\section{PIKÜNOGETUN}

Tüfa chi chijka zugu mew ta kintugeay chumgechi ta mufüke xipantu amulechi siglo XIX mew güxamyegey ta chem kimeltun pünegey kimeltuam ta che Chile mew, güxamyegey ta fey chi kimeltun re rulpakelu zugu, küzawtuniegefuy ta re logkontukual ka wüñofeypial kiñeke hemül ka kiñeke fey pin müten. Fey mew ta malügey kiñeke kuyfi chijka zugu xipalu fey chi ke xipantu femgechi ta azkintugey chemke zugu xipay fey mew chem pi ta che clericales ñi pepilkan ñi kimeltun, welu ka chem zugu mülefuy ta ñi feypigeal ñi zoy kaletuafel ta kimeltun fey chi ke xipantu mew. Femgechi ta tüfa chi chijka küzaw kejuay ñi pegelael chumgechi ta kuyfi zewma siglo XIX mew inaniegey ñi wüñoelgetuael ta kimeltun-azümün azkintunielu ta pu chijkatufe ñi pepiluwael egün.

Kimfal hemül: Revista historia de la educación latinoamericana; logko; azümün; kim kimeltun; modelo; kimeltuwün. 


\section{INTRODUCCIÓN}

Recurrente es encontrar en textos, discursos y reformas educativas latinoamericanas, propuestas pedagógicas dedicadas a que las didácticas educativas estén centradas en los estudiantes y en el desarrollo de habilidades que les permitirán desenvolverse de mejor manera en la sociedad; más aún, estos argumentos, en su mayoría, enfatizan que, para lograr este propósito, la actividad educativa no debe ser monótona ni repetitiva. Por cierto, estas valoraciones en el contexto chileno no son nuevas, ya que las estrategias de enseñanza basadas en la repetición de actividades que se limitaban al uso de la memoria como recurso de aprendizaje, comienzan a criticarse por medio de informes y documentos legales al menos desde la tercera década del siglo XIX.

Este estudio investiga, desde una óptica heurística, documentos y discursos representativos del siglo XIX, con diversos orígenes, entre ellos de intelectuales y políticos, tanto nacionales como extranjeros, que ayudaron a constituir las primeras bases educativas del primigenio Estado chileno y coadyuvaron, asimismo, a proponer un cambio en la enseñanza instaurada durante la Colonia, basada principalmente en principios religiosos. Por consiguiente, el propósito de este artículo es dilucidar cuáles fueron los motivos de estos actores para plantear un cambio de la estructura educativa. Crítica que a medida que transcurría el siglo XIX se fue intensificando y formalizando por medio de decretos, libros, manuales educativos, haciéndose presente la detracción en los diversos contextos educativos de la época: bachillerato, en la formación de preceptores y, de manera primordial, en la educación dedicada a la primera infancia. Por lo tanto, la relevancia de este estudio es demostrar que la crítica al uso de las estrategias memorísticas no es una cuestión contemporánea ${ }^{3}$, sino al contrario, ya tiene, al menos en Chile, casi dos siglos de antigüedad.

\section{Discusiones en torno a la enseñanza memorística durante la primera mitad del siglo XIX}

Los inicios educativos del Chile republicano son complejos, pues existía una universidad, la Real de San Felipe (la cuarta fundada en Chile $)^{4}$ y algunos colegios secundarios, todos ellos pertenecientes a órdenes religiosas ${ }^{5}$ y ninguna es-

3 El propósito del cambio que plantean los nuevos objetivos y contenidos en cada asignatura es dotar a cada alumno y alumna de herramientas intelectuales y morales que los habiliten plenamente para su vida como personas, trabajadores y ciudadanos en la sociedad del siglo XXI. Se entiende que tendencias seculares propias a la sociedad del conocimiento y el proceso de globalización le exigen al sistema escolar, mayor capacidad para formar en unas nuevas habilidades, o con mayor nivel e intensidad en unas habilidades que han sido objetivos de aprendizaje tradicionales. Entre estas destacan: capacidad de abstracción, pensamiento sistémico, experimentación y aprender a aprender, comunicación y trabajo colaborativo, resolución de problemas, manejo de la incertidumbre y adaptación al cambio. Al nuevo currículo se le exige, asimismo, desde la historia reciente del país, el desarrollo de habilidades y actitudes ciudadanas basadas en la valoración de la democracia y de los derechos humanos. Cristian Cox, "Política y políticas educacionales en Chile 1990-2010", Revista Uruguaya de Ciencia Política, Vol. 21, n. ${ }^{\circ} 1$ (2012): 25.

4 Primero se funda la Universidad Pontificia Santo Tomás de Aquino (1619), luego el Convictorio San Francisco Javier (1621) y ulteriormente la Universidad Pencopolitana de la Concepción (1724).

5 Véase Amanda Labarca, Historia de la enseñanza en Chile (Santiago de Chile: Imprenta Universitaria, 1939). 
cuela pública dedicada a la enseñanza de las primeras letras, creadas después de la Independencia. Durante esta etapa de la naciente república chilena, en 1813 se constituye en primer lugar el Instituto Nacional, institución que tuvo un repentino cierre y una pronta reapertura6; aquel, se suponía, significaba modificar la extensiva práctica formativa religiosa que había en Chile, con casi dos siglos de tradición. No obstante, su funcionamiento era similar a las instituciones educativas devotas que lo antecedieron ${ }^{7} \mathrm{y}$, posteriormente, casi una década después de la creación de este establecimiento educativo, se comienzan a decretar las primeras leyes para constituir escuelas primarias.

La constitución de 1822 dedicó el título VII a la educación pública señalando que esta sería uniforme en todas las escuelas. La de primeras letras debía haber al menos una en cada población, debían enseñar a leer y escribir, contar, los principios de la religión y los deberes del hombre en sociedad ${ }^{8}$.

Bajo este contexto, en Chile se comenzaron a implementar medidas educativas $^{9}$ y se trató de ir incorporando nuevas estrategias didácticas dentro del aula. Aunque el método y la manera de calificar, en el contexto del bachillerato y la universidad, seguían siendo similares a los utilizados durante la Colonia: rendir exámenes para aprobar los $\operatorname{cursos}^{10}$, las nuevas perspectivas educativas tenían como propósito que el estudiante no tan solo repitiera el contenido de memoria, sino que también tuviera la capacidad de aplicarlo y comprenderlo. Para ello, el gobierno de turno comenzó a implementar estrategias que apuntaron no solo al cambio de la gestión educativa, sino también a la mentalidad pedagógica:

El ilustre patricio don José Miguel Infante que, con un espíritu innovador, había procurado levantar de su postración la enseñanza pública, fue quien desde la suprema magistratura reorganizó el Instituto en 1826 y entregó a Lozier su dirección, autorizándole ampliamente para hacer una reforma completa con nuevos métodos de enseñanza y con nuevos sistemas de disciplina ${ }^{11}$.

En definitiva, la señal que enviaba la clase política emergente en la primigenia república chilena era buscar:

$6 \quad$ Luego de que el gobierno de O’Higgins hubiera decretado el restablecimiento del Instituto Nacional en 1819, vino su reorganización en el sentido de hacerlo un centro universitario, dividiéndolo, según leyes y reglamentos, en una sección de instrucción científica, otra industrial, y en un museo de instrumentos para las ciencias experimentales. Guillermo González, Memoria histórica de la Educación Pública en Chile, 1810-1900 (Santiago de Chile: Imprenta de Meza Hermanos, 1913), 42.

7 Ibíd. Nada se avanzó, sin embargo, en cuanto al régimen interno, obra de don Juan Egaña, que dejaba al Instituto sometido a la santa tutela del principio religioso.

8 Sol Serrano, Universidad y nación. Chile en el siglo XIX (Santiago de Chile: Editorial Universitaria, 1994), 46.

9 Para una revisión de las leyes promulgadas en aquella época, véase Ricardo Anguita, Leyes promulgadas en Chile desde 1810 hasta el 1.0 de junio de 1913 (Santiago de Chile: Imprenta, Litografía i Encuadernación Barcelona, 1913).

10 Véase Jesús Lara, "Aproximación histórica-educativa al primer sistema de evaluación usado en Chile: los exámenes para acceder el grado de bachiller, licenciado, maestro y doctor en Teología en la Universidad Pontificia Santo Tomás de Aquino", Cuadernos Chilenos de Historia de la Educación, n. ${ }^{\circ} 9$ (2018): 52-80.

11 Juan Conejeros, La influencia cultural francesa en la educación chilena, 1840 - 1880 (Santiago de Chile: Universidad Católica Cardenal Raúl Silva Henríquez, 1999), 46. 
[...] nuevos referentes paradigmáticos en el ámbito cultural, social y político que le permitan estructurar una nueva racionalidad ordenadora en el naciente y fundante Estado Nacional Republicano. La vertiente ideológica fundamental y dominante que recrea este nuevo universo simbólico lo constituye sin duda la Ilustración ${ }^{12}$.

Ideología que tuvo un fuerte impacto en Chile, pues la Ilustración tenía como idea central no tan solo la educación generalizada o universal, sino también la modernización de los estudios, los cuales debían aportar a la mejora de la nación $^{13}$. Principios que, sin lugar a dudas, cuadraban con las intenciones de este nuevo proyecto educativo ${ }^{14}$ que se comenzaba a desarrollar en esta joven nación del cono sur de América.

De manera que, el tema pedagógico se estableció como eje medular de la discusión y no tan solo a nivel gubernamental, sino también se realizaba por medio de la prensa de aquella época, espacio que servía para argumentar las diferentes posiciones que existían en torno al uso de la memoria como recurso de aprendizaje. Por cierto, uno de los aspectos fundamentales en esta materia fue que a Chile comenzaron a llegar intelectuales de otras latitudes de América, los cuales, junto con los chilenos que estaban en este mismo camino, proponían cambios en materia educativa.

Se ha sostenido que Bello defendió en El Araucano contra don José Miguel Infante, redactor de El Valdiviano Federal, que el derecho romano debía enseñarse en latin $i$ de memoria.

Este es un error.

Bello pensaba que en medio del desorden de las leyes españolas, convenía estudiar la lejislación romana, que era la fuente de aquéllas i que constituía un cuerpo homojéneo i armónico.

Recomendaba tambi[é]n, es cierto, los comentarios de Vinnio; pero se hallaba mui lejos de sostener que el estudio de memoria era el m[á]s fructífero.

Por el contrario, se sabe que el ilustre maestro adoptaba en sus lecciones a los jóvenes el sistema de conversación, o sea de preguntas i respuestas. ${ }^{15}$

Independiente de quien tenga la razón en esta controversia realizada en la prensa escrita de esa época, pues no es tema de este artículo dilucidar esta cuestión, lo que interesa es la disputa en torno a la forma de enseñar, pues, por lo que podemos observar en la cita anterior, se proponen dos posiciones: la primera tiene que ver con la instrucción clásica, de tipo más escolástico y, la segunda, sostenida en la dialéctica y las indagaciones, viene a romper con esta tradición.

12 Ibíd., 18.

13 Jesús Lara, "La influencia dominica en la Universidad Real de San Felipe y el traspaso a un modelo borbónico de educación", en Saberes y poder. Colegios y universidades durante el reformismo borbónico, ed. Benito Moya (Córdoba: Ediciones Universidad Católica de Córdoba, 2015).

14 Un estudio que serviría para hacer un análisis comparativo con la construcción de la nación y las nuevas miradas de las jóvenes naciones latinoamericanas lo encontramos en Roger Pita, "Fundar escuelas para consolidar la República y formar ciudadanos. Una aproximación para el caso colombiano", Revista historia de la educación latinoamericana, Vol. 17, n.o 25 (2015).

15 Domingo Amunátegui, Los primeros años del Instituto Nacional (1813-1835) (Santiago de Chile: Imprenta Cervantes, 1889), XV. 
Esto nos indica que ya, para la tercera década del siglo XIX, algunos intelectuales chilenos y extranjeros comprendían que los usos de mecanismos monótonos de enseñanza no desarrollaban a cabalidad la comprensión de los contenidos. A propósito, es preciso señalar que Andrés Bello tenía una postura anticlerical, por lo tanto, no debiera sorprender que su actitud pedagógica fuera contraria a lo que proponían los métodos religiosos de enseñanza.

Las nuevas posiciones pedagógicas que emergían en Chile durante esta época, principalmente inspiradas en corrientes europeas ${ }^{16}$, sobre todo en la primera mitad del siglo XIX, surgían desde la crítica que se hacía al modelo clerical de enseñanza, el cual, como mencionamos anteriormente, había imperado durante más de dos siglos en este territorio, propuestas que nacían, sin duda, desde la separación de la Iglesia con el Estado. Esta división trajo consigo otras posturas educativas, y en este sentido, vale la pena recalcar que la herencia educativa de la Colonia seguía con vida por medio de sus diversos establecimientos educativos, principalmente los pertenecientes a las órdenes religiosas, los cuales eran privados. En las instituciones formativas devotas las estrategias memorísticas eran usadas como un mecanismo de control y de vigilancia, pues los exámenes se hacían para controlar el dominio de los contenidos y la forma en que estos se aprendían. Justamente, era esta práctica la que se quería erradicar, pues la educación se comenzaba a entender no como un mero mecanismo de repetición, sino más bien como la comprensión de los conceptos adquiridos. Esto es algo que José Abelardo Núñez percibió de buena manera, por lo que señaló: "Puede decirse, en general, que sólo los métodos y el sistema disciplinario antiguo seguían imperando"17.

Lo anterior nos indica que el cambio más grande, pos-Independencia, se había producido en términos de gestión y visión de la educación, ya que en las aulas predominaba el uso de métodos instructivos mecánicos.

La gramática de los antiguos escolásticos con sus interminables definiciones i reglas oscuras que el alumno no podía comprender; i destinada solo a ejercitar su memoria, ha sido desterrada por completo de los estudios primarios en la educación moderna, $i$ se ha abierto al mas ancho $i$ vasto campo al estudio del lenguaje, asi hablado como escrito, haciendo de él la base de los conocimientos que mas tarde han de completar la educación del alumno con el aprendizaje de los preceptos de la gramática i la retórica ${ }^{18}$.

Particularmente, estas opiniones venían desde actores políticos y sociales relacionados con el Estado emergente chileno, y se hicieron evidentes por medio de diversos documentos que conviene destacar, como: "Informes de exámenes

16 Véase Conejeros, La influencia cultural francesa.

17 Gonzalo Latorre, La vida ejemplar de José Abelardo Núñez Murúa, 1840-1910 (Santiago de Chile: Escuela Nacional de Artes Gráficas, 1944), 16.

18 José A. Núñez, Estudios sobre educación moderna. Organización de Escuelas Normales (Santiago de Chile: Imprenta de la Librería Americana, 1883), 163. 
del Instituto Nacional"19, que corresponden a la primera mitad del siglo XIX, en los cuales se observan críticas al uso de la memoria como recurso de aprendizaje; Consejos sobre educación, tomados de M. Th. H. Barrau ${ }^{20}$, documento publicado en 1868 en el que se criticó el uso de estrategias de enseñanzas basadas solo en la repetición. Este manuscrito estaba orientado a la formación de preceptores. Para finales del siglo XIX los libros de textos educativos se unen a la crítica de las didácticas repetitivas, por ejemplo, Nuevo método (fonético, analítico-sintético) para la enseñanza simultánea de la lectura i escritura, publicado en $1884^{21}$, texto que se inspiró en la pedagogía alemana y en autores suecos de renombre de la época, como Pestalozzi ${ }^{22}$. Hubo, por supuesto, otros documentos escritos con el mismo tenor argumentativo, pero los escogidos se pueden considerar como los más representativos.

En esencia, estos escritos planteaban de manera rígida un cambio en la forma de enseñar, pues tenían como propósito orientar las prácticas pedagógicas al desarrollo de los sentidos, dado que los argumentos teóricos de ese período señalaban que en las percepciones se almacenaba la experiencia y desde la experiencia se podían vincular los aprendizajes con los mecanismos internos del cerebro, es decir, usar una mayor capacidad cognitiva puesto que la idea era no limitar el uso de la mente sino, al contrario, ampliarla. Propuestas que se fundamentaban, indudablemente, de la revolución pedagógica planteada por Comenio, Locke y Pestalozzi, quienes proponían conectar la actividad intelectual con las experiencias vividas, o dicho de otro modo:

Establece este principio un modo de acceso al conocimiento cuyas características básicas son lo sensible, lo observable, lo experimentable, lo inmediato y lo directo, cuyos referentes básicos son las relaciones con el exterior a través de los sentidos, pero no son los únicos, pues se valoran los aspectos internos ${ }^{23}$.

Es decir, aquellos autores - referentes de la intelectualidad chilena -, sugerían la integración mental como estrategia didáctica para lograr con el educando un proceso de construcción intelectual óptimo, una unificación cognitiva que solo se alcanzaría por medio de la comprensión de los contenidos. Se concebía la idea de que los estudiantes debían usar su conocimiento empírico para entender y resolver problemas y, por ello, planteaban que la información debía ser almacenada para conectarla con los conocimientos previos que el educando tenía, no solo de forma repetitiva, pues el poder vincular lo conservado en la memoria con las experiencias previas permitía internalizar de mejor manera los contenidos asociados con los aprendizajes. Este cambio conceptual de la educación

19 Véanse Amunátegui, Los primeros años; o los Anales de la Universidad de Chile. Tomo XX, correspondiente al primer semestre de 1862 (Santiago de Chile: Imprenta del Ferrocarril, 1862).

20 José A. Núñez, Consejos sobre educación, tomados de M. Th. H. Barrau (Santiago de Chile: Imprenta Nacional, 1868).

21 Claudio Matte, Nuevo método (fonético, analítico-sintético) para la enseñanza simultánea de la lectura i escritura (Leipzig: Imprenta de F. A. Brockhaus, 1884).

22 Juan Mantovani, Juan Enrique Pestalozzi (Guatemala: Universidad San Carlos de Guatemala, 1946).

23 Ramón Pérez, El curriculum y sus componentes. Hacia un modelo integrador (Barcelona: Oikos-Tau, 1994), 115. 
fue fundamental para proponer reformas en el sistema educativo chileno. Al respecto, Jaume Carbonell nos señala la siguiente idea que explica de qué forma las nuevas argumentaciones pedagógicas de la época se encargaron de sustituir o repensar los antiguos discursos y prácticas educativas:

"[...] una obsesión, deliberada o inconsciente, por borrar el pasado colectivo, por desterrar de los discursos educativos actuales los referentes y las raíces sobre los cuales han crecido y cristalizado las ideas y las prácticas pedagógicas más innovadoras de nuestro tiempo"24.

Este fue el discurso que se instaló en el colectivo-educativo de la época y sirve para entender de qué modo comenzaron los intentos de eliminar la pedagogía escolástica, la cual solo se entendía como un recurso mecánico. El análisis que cita Carbonell es pertinente para explicar el cambio del constructo teórico, respecto a la idea de educación que se había implantado en Chile por medio de debates, congresos, proyectos e informes durante el siglo XIX, ya que este autor nos advierte de qué manera los conceptos o ideas educativas se van construyendo de acuerdo con el contexto histórico en el que surgen porque: "Todo concepto es histórico, oscilántico, dinámico, cíclico y dialéctico, se configura en forma de zigzag. Al estilo del vuelo de las mariposas, dialogando con sus propias tensiones, paradojas y contradicciones" 25 .

La rigidez de esa época, además de contener elementos políticos e ideológicos, estaba concentrada en la discusión sobre las didácticas de enseñanza, también en la forma de entender el desarrollo psicológico y cognitivo de los estudiantes, pero además en la manera de transmitir o enseñar los contenidos por parte de los preceptores. La construcción de la nueva interpretación del concepto memoria, se comenzaba a resignificar desde la crítica, puesto que a la repetición memorística no se la veía como una alternativa fecunda, sino al contrario, se la entendía como una práctica mental estéril; al respecto Muñoz nos señala: "Incumbía desterrar la aridez de la enseñanza religiosa en las escuelas chilenas" ${ }^{26}$.

Por otro lado, el comenzar a tener otra mirada de la educación, así como los constantes intercambios de ideas con pensadores de otras geografías, particularmente de Europa, reformaron la manera de entender la infancia y el desarrollo del educando, el cual comienza a ser visto, ya no como un mero ejecutor de tareas repetitivas, sino también como un ser que debía tener la capacidad de comprender lo que ejecutaba, es decir, la educación era comprendida como la oportunidad de amplificar y potenciar el desarrollo de la mente, argumentos relacionados, como lo mencionamos anteriormente, con uno de los referentes de consulta obligado de aquel tiempo en Chile, Juan Enrique Pestalozzi, quien señalaba lo siguiente con respecto al uso de la memoria: "Si por ejemplo, apren-

24 Jaume Carbonell, Pedagogías del siglo XX (Barcelona: Editorial CISSPRAXIS, 2000), 5.

25 Alexander Ortiz, "Configuración epistémica de la pedagogía. Tendencias que han proliferado en la historia de la educación”, Revista historia de la educación latinoamericana, Vol., 19, n.o 29 (2017): 18.

26 José Muñoz, Historia elemental de la pedagojía chilena (Santiago de Chile: Sociedad Imprenta y Litografía Universo, 1918), 230. 
demos únicamente de memoria: tres y cuatro son siete y en seguida contamos con ese siete como si supiéramos realmente que tres y cuatro son siete, nos engañamos a nosotros mismos" 27 .

En teoría, en Chile iba quedando atrás una manera de entender la instrucción por medio de tareas iterativas o de transferencia de información. En este sentido, el estandarte educativo que aún quedaba en pie en la primera mitad del siglo XIX, la Universidad Real de San Felipe, representativa de un modelo colonial, vivía sus últimos suspiros pues sus estrategias ya no servían al propósito de los nuevos gobiernos de turno.

Pero la Universidad de Felipe V no satisfacía ya las aspiraciones del país. Sus estudios, cuyos programas ocupaban casi por entero la Teología y la Filosofía escolástica, se hacían en latín. Se conservaba en ella, como en los colegios conventuales, aquellos estudios perjudiciales e inútiles, aquel bárbaro ejercicio de la memoria, aquella ridícula aficción a las sutilezas y a las vanas investigaciones, como si los estudios que debian dirigirse a perfeccionar el intelecto, se hubieran establecido para disertar y discutir con refinamiento sobre creaciones abstractas ${ }^{28}$.

Quizás la crítica a las didácticas fue solo un motivo para comenzar a instaurar nuevas directrices educativas; el modelo educativo republicano no tan solo quería desarrollar la capacidad de reflexionar sino también que esta habilidad fuera útil para el desarrollo del país, es decir, para el crecimiento económico. Esto no se iba a lograr, según los críticos, empleando estrategias monótonas que limitaban el uso del razonamiento humano.

Ya en 1811 se ven luces de estos planteamientos, cuando recién comenzaba la planeación de la primigenia república, pues si bien en la época de su creación, el Instituto Nacional aún estaba apegado a la escolástica, sobre todo en sus estrategias y principales materias educativas dictadas, se proponía a este establecimiento como el precursor de la formación de esas ideas e intelectos que el país necesitaba:

En 1811 [Camilo Henríquez] había presentado al Congreso Nacional un plan de organización del Instituto Nacional de Chile, "escuela central y normal para la difusión y adelantamiento de los conocimientos útiles".

Alli exponía que "el fin de la educación es dar a la patria ciudadanos que la defiendan, la dirijan, la hagan florecer y le den honor"29.

Para que esto se concretara era necesario reformular las didácticas empleadas hasta ese entonces en el sistema educativo, sobre todo en el laico, y el desprendimiento de la Iglesia-Estado dio ciertas libertades para comenzar a promover

27 Juan Enrique Pestalozzi, Cómo Gertrudis enseña á sus hijos, trad. por José Tadeo Sepúlveda (Coatepec: Tipografía de Antonio M. Rebolledo, 1889), 177.

28 González, Memoria histórica, 82.

29 Ibíd., 30. González cita y se refiere a Camilo Henríquez (1769-1825), sacerdote, escritor y político, prócer de la independencia de Chile. 
tendencias y miradas pedagógicas alternativas para la época. No obstante, en el Instituto Nacional, institución representativa del cambio, se siguieron usando metodologías abstractas y repetitivas. Esto nos indica que existía un doble discurso y que lo explícito de los documentos, declaraciones y argumentos que proponían el cambio, en la realidad no se cumplía pues algunos preceptores seguían recurriendo a la memorización como única práctica educativa, un indicador histórico que nos entrega un mensaje importante: las reformas educativas se hacen en dos frentes: en la práctica y en la teoría. Esto queda evidenciado en los informes que realizaron los profesores examinadores de estudiantes, pues en ellos establecen que el uso de la memoria como "repetición verbal" seguía siendo el gran problema educativo:

Los exámenes de Historia antigua i griega de los estudiantes de Humanidades del Instituto Nacional me causaron una impresión bastante desagradable. En jeneral, los alumnos sabían bien poca cosa; i pude notar que se les había enseñado el texto puramente de memoria, sin que los jóvenes pudieran darse cuenta de las frases que repetían ${ }^{30}$.

Estos relatos ya dan cuenta que el repetir o conocer conceptos no necesariamente sirve para entender un proceso histórico, pues la reproducción de contenidos sin la comprensión temática de lo estudiado no permitía en los estudiantes desarrollar nuevos argumentos, no los facultaba para debatir y no los preparaba para interpretar los textos. Por tanto, para la mirada de los examinadores, que querían evaluar otras competencias de los examinados, y estos, al estar acostumbrados solo a retener conceptos, quedaban imposibilitados para responder a las preguntas analíticas o de relación de hechos, ya que en su entrenamiento educativo solo se les había enseñado a repetir palabras o frases sin entendimiento del significado. La información incorporada en las memorias de los estudiantes evaluados no servía porque no tenía un uso práctico, no la conectaban con otros hechos o causas, pues la única forma de utilizar este conocimiento iterativo era por medio de la reproducción de respuestas aprendidas de memoria. Es el mismo examinador quien enfatiza lo siguiente: “Con este sistema, los alumnos estaban completamente imposibilitados para contestar a las preguntas sueltas que les dirijí, i aun para explicar el verdadero sentido de las metáforas del texto; pero en cambio, las repetían con bastante facilidad."31.

Evidente es que la mnemotecnia era la estrategia usada por antonomasia para educar durante ese período, pero este tipo de recurso ya había perdido su prestigio, puesto que no se le veía utilidad para las nuevas necesidades del país y por consiguiente se requería que los educandos tuvieran al menos la capacidad de interpretar hechos, frases, ideas; en otras palabras, la mirada educativa republicana proponía una educación basada en la comprensión de los sucesos,

30 Anales de la Universidad de Chile, 199.

31 Ibíd. 
en la cual los estudiantes pudieran responder preguntas basados en el conocimiento y el entendimiento de los conceptos: no en la mera repetición mecánica.

\title{
Influencias pedagógicas para una propuesta de cambio educativo
}

Esta crítica al uso de enseñanzas mecánicas fue un tema medular durante el siglo XIX en Chile, razón por la cual hubo políticos que, interesados en el tema pedagógico, comenzaron a leer literatura de otras latitudes que ofrecía otra mirada y variantes didácticas a la enseñanza y aprendizaje. La memoria como único recurso de aprendizaje y calificación, insistimos, en teoría, no en la práctica, era cosa del pasado. Asimismo, la incorporación de profesionales y técnicos de otras regiones del continente americano y de Europa fue un procedimiento habitual durante casi todo el decimonónico, porque el pensamiento educativo escolástico heredado de la Colonia se quería erradicar por medio de argumentos no tan solo nacionales, sino también de inmigrantes que se identificaban con las prácticas educativas anti-escolásticas. En este sentido, el comentario de Luis Pradenas es bastante claro:

\begin{abstract}
Desde Europa, y para permanecer durante años o definitivamente en el país, llega un importante número de científicos, técnicos, profesionales, y artistas que, en su mayor parte contratados por el gobierno, vienen a sumarse al esfuerzo de las elites criollas por dar a la joven república el rango de país civilizado.

Políticos e intelectuales criollos, hispanoamericanos y europeos, constituyen la "comunidad cosmopolita" que, organizando la institucionalización del Estado y el sistema educacional, se impone como vanguardia en el proceso de construcción de la modernidad y de refundación simbólica y política de la nación $n^{32}$.
\end{abstract}

Esta idea, la de seguir ideas y modelos extranjeros, tampoco es del todo nueva en Chile, dado que, el "modo de operar", para observar el estándar de progreso de otras naciones como guía para la nación chilena, ha estado siempre centrado en la búsqueda de respuestas fuera de nuestro contexto o realidad. Esto nos indica que las políticas para diseñar el curriculum en la educación chilena siempre se han fundamentado en esquemas de proyectos educativos de otras geografías. Un ejemplo de ello es la erección de la Real Universidad de San Felipe ${ }^{33}$ (1737) y su antecesora, la Universidad Pontificia Santo Tomás de Aquino (1619), ambos modelos inspirados en la Universidad de Salamanca y Alcalá de Henares, respectivamente ${ }^{34}$.

32 Luis Pradenas, Teatro en Chile. Huellas y trayectorias. Siglos XVI-XX (Santiago de Chile: LOM, 2006), $152,153$.

33 José Medina, Historia de la Real Universidad de San Felipe de Santiago de Chile (Santiago de Chile: Imprenta y Litografía Universo, 1928).

34 La Universidad Real de San Felipe no tan solo tenía similitudes con los exámenes empleados en el viejo continente, sino también semejanzas notorias con los exámenes que se practicaron en la Universidad Conventual Dominica que la precedió, situación que no es extraña dado que, ambos modelos, estaban inspirados en casas educativas europeas: Salamanca y Alcalá de Henares. Lara, "Aproximación histórica-educativa", 69. 
De modo similar a como se actuó en el principio de nuestra construcción educativa, a principios del siglo XVII y, luego, a lo largo del siglo XIX, se seguían buscando respuestas organizativas y educativas en otras latitudes; ahora bien, el sustento que se examinaba en el decimonónico era diferente, pues ya no se quería seguir el patrón religioso como fundamento pedagógico, sino un tipo de modelo que apuntara a cambiar las formas de enseñanzas escolásticas por uno más idóneo a la realidad de una naciente nación. No obstante, aunque el fundamentado educativo que se consultaba era diferente, se repetía la estrategia de esa búsqueda de información: observar otros países para imitar sus fundamentos e ideas educativas.

Que se utilizara la estrategia de prestar atención a modelos educativos de otras regiones del mundo para instaurarlas como esquema predominante ha sido un camino difícil de abandonar en nuestra historia educativa, pues esta forma de actuar se consolidó en el tiempo como un proceso repetitivo y mecánico, lo cual es irónico y contradictorio, pues, aunque las buenas intenciones y, sobre todo, las críticas para cambiar el modelo educativo imperante, basadas en el uso de la memoria repetitiva como único mecanismo de aprendizaje, aquellos que proponían cambios no tenían la facultad de crear modelos propios, contextualizados, sino que se fundamentaban en lo existente; era más fácil seguir patrones creados que innovar. No obstante, esto no significó que la práctica educativa fuera llevada a cabo sin una mirada reflexiva interna, aunque buena parte del sustento provenía de teorías de otras realidades.

Ahora bien, lo positivo de comenzar a intercambiar con profesores, intelectuales o pedagogos de otros países fue que se incrementaron las posibilidades de cambio; por ejemplo:

Don Rodulfo Amando Philippi fue elegido profesor de botánica, en 1854, cátedra
que desempeño hasta que fue elegido en su reemplazo su hijo Federico, el año 1874 .
Philippi era, ante todo, un naturalista al estilo alemán, de conocimientos a la
vez vastos y profundos. La botánica (historia natural) empezó a enseñarla entre
nosotros de una manera práctica y atrayente; se estimaba básica para aprender
más tarde materia médica y terapéutica. Con la enseñanza de Philippi comienza
a infiltrarse, lenta, pero seguramente, el método acucioso y fino de la observación,
el de la comparación y el de la deducción. El antiguo aprendizaje de memoria, tan
frecuente entre nosotros, fue modificándose; Philippi acostumbraba a sus alumnos
al ejercicio mental, a pensar por su propia cuenta, demostrando el propio discerni-
miento y apreciación ${ }^{35}$.

Estos contrastes didácticos entre lo nacional y lo internacional fueron relevantes y significativos, pues permitían comparar las prácticas educativas internas con las traídas de otras zonas, lo cual significó que José Abelardo Núñez, particularmente, comenzara a realizar una intensiva crítica y autocrítica respecto a la formación de preceptores en las Escuelas Normales de Chile; incluso en 1883

35 Fernando Campos, Desarrollo educacional 1810-1960 (Santiago de Chile: Editorial Andrés Bello, 1960), 142. 
publicó un interesante estudio, Estudios sobre educación moderna, organización de Escuelas Normales, período que coincide con una de las décadas con más cambios estructurales, teóricos y políticos, sobre todo en el ámbito educativo, durante todo el siglo XIX en Chile. Por lo que se refiere al informe, su resultado es lapidario y nos muestra, en parte, cómo era la formación del preceptorado en esos años, carente de uso de material concreto o material complementario para que los estudiantes desarrollaran la imaginación, los sentidos y no tan solo aprendieran conceptos de memoria que, luego, no serían útiles en su aprendizaje.

La enseñanza que en el día se da en nuestras Escuelas Normales en materia de jeografia es tan deficiente, que en algunas de ellas se carece de cartas jeográficas modernas, haciéndose uso solo de algunas mui elementales i antiguas. Por lo dem[á]s, ese estudio se encomienda esclusivamente a la memoria, i los métodos de enseñanza racional permanecen ignorados por completo ${ }^{36}$.

José Abelardo Núñez fue parte de un grupo de políticos que, interesados en el tema educativo, comenzaron a viajar a Europa y Estados Unidos para conocer y extraer ideas en materia educativa, e incorporarlas en Chile. "Estos viajes le permitieron estar al tanto de corrientes pedagógicas modernas: se pone en contacto con la literatura pedagógica europea y norteamericana y lleva al terreno de la práctica misma, en escuelas de la sociedad las innovaciones más recientes y prestigiadas" ${ }^{\prime 37}$. Ahora bien, décadas antes había realizado una tarea similar Domingo Faustino Sarmiento ${ }^{38}$ y consultó a los mismos teóricos que Núñez, como Horace Mann. Las preocupaciones de Sarmiento también estuvieron enfocadas en el cambio de los métodos didácticos y en emplear modelos educativos de otras realidades en Chile.

Con respecto a la apertura y roce educativo que vivió Núñez, estas experiencias lo facultaron para formular proyectos educativos diferentes a los que solo proponían recordar hechos sin comprenderlos, razón que lo llevó a escribir libros y presidir congresos en los cuales se debatieran estos temas. Por otro lado, también se preocupó de la formación de preceptores, pues en ellos recaía la responsabilidad de generar los cambios en la práctica, en el aula, que es donde se debían comenzar a ejecutar las reformulaciones educativas.

36 Núñez, Estudios sobre educación moderna, 209.

37 Latorre, La vida ejemplar, 11.

38 "Terminado el primer curso de normalistas, Sarmiento fué nombrado comisario de educación en Europa i Estados Unidos, para estudiar la organización escolar, sistemas i métodos de enseñanza. Partió a Francia a fines de 1845, recomendado al ministro de Chile don Javier Rosales. Presentado a Mr. Guizot, obtuvo toda suerte de facilidades para visitar los establecimientos de instrucción. De la escuela normal de Versalles tomó notas minuciosas. Las escuelas primarias, las salas de asilo, las cunas o casas de lactancia, le merecieron particular atención.

“En España, autorizado por el Ministro de instrucción don Antonio Jil i Zárate, recojió cuantos datos deseaba reunir acerca de los métodos de lectura i escritura, con la consulta de manuscritos antiguos. Se incorporó a la Sociedad de Profesores de Madrid.

"Recorrió la Italia, Prusia i Holanda, para informarse del réjimen de las escuelas normales, escuelas primarias i de sordomudos, circunscribiendo sus observaciones al objeto preciso de su encargo. En Londres se concretó a inspeccionar las escuelas primarias, completando con la consulta de obras especiales sus notas obre la educación inglesa.

"Trasladado a Estados Unidos, inspeccionó las escuelas de diversas ciudades, conferenciando con los educacionistas más prominentes. Trató a Cirus Pierce, director de la primera escuela normal anglo-americana; i a Horacio Mann, que dos años antes había desempeñado igual comisión en Europa”. Muñoz, Historia elemental, 123-124. 


\section{Intensificación de la crítica al uso de la memoria como único recurso de aprendizaje durante la segunda mitad del siglo XIX}

La segunda mitad del siglo XIX fue más intensa en esta materia y en ella se plasmaron, como se mencionó, proyectos, reformas, libros educativos, entre otros. El contacto permanente con las teorías vanguardistas que comenzaron a implementarse en Chile significó una profunda radiografía interna que venía siendo alimentada desde los orígenes de la república chilena pero intensificada en el último período de ese siglo, al igual como ocurrió en Europa y Estados Unidos, geografías de referencia para los nuevos planteamientos educativos chilenos.

Y, de igual modo que en Europa, en Estados Unidos "La enseñanza pasaba así a ser vista como instrumento de construcción politica y social". Este hecho obliga a puntualizar lo siguiente: Si bien los cambios registrados en educación a finales del siglo XIX, en lo que respecta a la creación de más escuelas y a una extraordinaria incorporación de niños y jóvenes a la formación escolar, constituyó el detonante para que se procediera inicialmente a la revisión crítica de los medios tradicionales de la enseñanza tradicional, y se centrara la atención de la educación en el desarrollo individual de las capacidades y aptitudes [... $]^{39}$.

Este análisis crítico en Chile, así como en Europa y Estados Unidos, permitió comenzar a reestructurar nuevas definiciones en torno a la memoria como didáctica educativa; ahora bien, aunque la memoria desde el punto de vista de la neurología se entienda como la codificación, organización y almacenamiento de sucesos pasados, los críticos de este recurso apuntaban a la pobreza de su uso, pues los métodos escolásticos, al parecer, solo la usaban como recurso de almacenamiento y repetición de hechos ocurridos. Todo lo que tenía relación con experiencias previas o el significado de los recuerdos, no estaban contemplados en las didácticas pre-republicanas.

Por esta razón eran tan bien vistos todos aquellos argumentos pedagógicos y filosóficos que apuntaran a darle una resignificación a la educación: "La educación ha recibido, pues el soplo benéfico del espíritu filosófico moderno aceptando el análisis y aplicando a la enseñanza el proceso experimental" ${ }^{\prime 40}$. Lo empírico se incorporaba dentro de las estrategias educativas y redundar en la repetición de conceptos moralizantes ya no tenía sentido. Quizás esta era una de las grandes críticas que se le hacía a la educación clerical, que estaba diseñada no para reflexionar o potenciar el pensamiento sino para enseñar conceptos valóricos incuestionables, tanto a los fieles devotos como a los estudiantes de sus escuelas, obligados a creer y profesar.

Por otra parte, en las escuelas del gobierno se comienzan a realizar experiencias internas para reelaborar las prácticas educativas aún existentes a

39 Eleazar Narváez, “Una mirada a la escuela nueva”, Educere, Vol. 10, n. 35 (2006): 634.

40 González, Memoria histórica, 90. 
finales del siglo XIX; lo sorprendente es que estas innovaciones fueron usadas con temáticas cristianas y moralizantes:

Las lecciones modelos de historia bíblica, combinadas con el catecismo, pasaron a ser narraciones deliciosas para los niños; diálogos animados en que los niños discurren, impregnando la mente con hermosos recuerdos del pasado, tonificando su sensibilidad con el deleitoso sabor de las acciones injenuas, para elevar sus corazones mediante ejemplos que los encantan. I todo eso sin aprender nada de memoria ${ }^{41}$.

Por cierto, estas didácticas eran empleadas, principalmente, por profesores extranjeros, como Eduardo Rossig ${ }^{42}$, de procedencia alemana, desde donde llegaron innumerables docentes para promover la reestructuración de la pedagogía tradicionalista empleada en Chile hasta ese momento. Asimismo, se aprecia que estas lecciones moralizantes suscitaban un clima acogedor, participativo, lúdico, en las cuales los profesores estimulaban a sus estudiantes a usar la memoria no como una función cerebral estática o aislada, sino más bien como un amplio recurso cognitivo en términos de clasificar, codificar, almacenar y recuperar información ${ }^{43}$, pero esto último con fines prácticos, es decir, no solo para repetir lo escuchado sino con el fin de vivenciar los hechos, imaginarlos. Esto permitía, además, en teoría, que los infantes relacionaran los contenidos aprendidos con sus propias experiencias.

En cierto modo, lo que comienza a ocurrir con estas nuevas experimentaciones pedagógicas es que se empezaron a integrar variantes distintas a la crítica que se había realizado respecto a las estrategias memorísticas hasta ese entonces, pues aquellas empezaron a abordar otros aspectos; ya no solo el uso de los sentidos era lo primordial, sino también el intento de contemplar las emociones de los estudiantes en sus estrategias, o dicho de otra manera:

Los modos de recordar son afectados por cambiantes valores mnemotécnicos: supuestos culturalmente arraigados sobre lo que es valioso recordar, lo que merece o no hay necesidad de que sea recordado, cómo los fragmentos de la memoria deben encajar, qué tipos de tarea de la memoria esperan servir ${ }^{44}$.

Y para las propuestas educativas chilenas de fines del siglo XIX recordar conceptos catequísticos ya no era lo más valioso pues esta idea, transmitida desde la Colonia y en el desarrollo de la República, era vista como una propuesta

41 Muñoz, Historia elemental, 230.

42 Eduardo Rossig fue un ilustre profesor alemán contratado por el gobierno chileno, que ocupó el cargo de subdirector de la Escuela Normal de Preceptores, director del Museo de Instrucción Primaria y profesor de Historia Natural. Entre sus obras se encuentra el libro Manual de práctica escolar (Santiago de Chile: Imprenta Roma, 1896).

43 Para revisar detalles sobre los sistemas de memoria, véase Paul Carrillo, "Sistemas de memoria: reseña histórica, clasificación y conceptos actuales. Primera parte: Historia, taxonomía de la memoria, sistemas de memoria de largo plazo: la memoria semántica", Salud Mental, Vol. 33, n.o 1 (2010).

44 Kurt Danziger, "Does memory have a history?", en Marking the Mind: A History of Memory (New York: Cambridge University Press, 2008). "La memoria, ¿tiene una historia?", traducción de Hernán Scholten y Sebastián Benítez, Cátedra I de Historia de la Psicología (Buenos Aires: Facultad de Psicología, UBA, 2012), 7. 
"recalcitrante" que se alejaba de las concepciones pedagógicas que centraban sus teorías en el desarrollo de la infancia como idea central, la cual posicionaba al ser humano como un ser racional y con capacidad de autodeterminarse. Los métodos religiosos, en el plano teórico, los cuales tienen su mayor preocupación en el mensaje cristiano, comienzan a ser relevados, pues:

[...] tienen que justificarse frente a la razón y la secular experiencia humanacomo, por ejemplo, en Lessing-o son entendidas como manifestaciones simbólicas, como equivalentes o preestadios del conocimiento racional a lograr por medio de la reflexión-como en el caso de Herder o, aunque con fundamentación diferente, el de Hegel-, o bien como mensajes conciliables con la autointerpretación del hombre como ser racional en potencia ${ }^{45}$.

El individuo que se educaba en Chile, según las nuevas propuestas pedagógicas, particularmente discutidas primero por Sarmiento a mediados del siglo XIX, luego por José Abelardo Núñez y Claudio Matte, entre otros, para finales de ese siglo era comprendido y entendido como una persona con derecho a pensar y repensar la información recibida por medio de la educación formal.

Los educandos, en todas sus dimensiones, comienzan a ser vistos como sujetos del aprendizaje y no como objetos; en palabras de Klafki, refiriéndose a Humboldt, otro referente importante del cambio educativo chileno: "[...] el proceso educativo es concebido por él [Humboldt] también como un proceso, abierto hacia adelante, de mediación de los sujetos con el mundo histórico y natural" ${ }^{\prime 4}$.

Esa conciliación no estaba presente en los métodos escolásticos, pero sí en los referentes de consulta de esa época; por ejemplo, Pestalozzi señalaba que era necesario combinar en la didáctica de enseñanza cabeza, corazón y manos, es decir, educar desde el interés del estudiante, concepción que también fue utilizada por Herbart, autor que de igual manera fue usado en Chile como fundamento de los cambios educativos, y cuyos pensamientos se aprecian principalmente a través de los argumentos de José Abelardo Núñez.

Citar consecutivamente en este artículo a José Abelardo Núñez está más que justificado por cuanto este intelectual se dedicó al estudio e investigación de una pedagogía orientada al desarrollo de los sentidos y no solo al uso de la memoria como recurso mecánico; en sus diferentes viajes e intervenciones en congresos, los cuales organizó, también criticó ese sistema, llegando a sostener lo siguiente:

"En la escuela moderna -dice-, al estudio de la palabra ha venido a sustituir la observación y la contemplación directa de las cosas; a la memoria ejercitada mecánicamente, el juicio; a la letra muerta del texto, la actividad de la inteligencia; a la

\footnotetext{
45 Wolfgang Klafki, "La importancia de las teorías clásicas de la educación para una concepción de la educación general hoy", Revista de Educación, n.o 291, (1990): 107.

46 Ibíd., 113.
} 
imposición de las ideas sin comprenderlas, el ejercicio del espíritu que investiga, compara y juzga"47.

Quedan claras las influencias que el autor chileno recogió de sus viajes por Europa y Estados Unidos, país de Horace $\mathrm{Mann}^{48}$, cuya concepción social y económica de la educación igualmente se considera fundamental; Mann concebía a la escuela como el espacio donde se deben enseñar y aprender las habilidades necesarias para desempeñarse laboralmente, principios asimismo presentes en Herbart. No obstante, aquellos territorios también comenzaron a ver la escuela como un lugar donde se podía potenciar el desarrollo de la mente o, dicho de otro modo, trabajar desde el contexto individual del educando, porque se entendía en estas nuevas propuestas educativas que el aprendizaje variaría de acuerdo con la cantidad de conceptos que estén disponibles en la mente, pero la forma para que esa adquisición de información sea utilizada por los sentidos dependerá de la manera como fueron adquiridos esos conceptos; aquellos alcanzados solo por medio de la repetición no tendrán más que un uso mecánico, pero los que fueron logrados por medio de experiencias concretas, experimentales y además conectados con el almacenamiento de la información, permitirán tener un conocimiento integrado de las cosas, es decir, comprensivo.

Estas teorías alimentaron la necesidad de promover reformas educativas en Chile, lo cual se concretó en 1884 y se acompañó de diversos materiales educativos y congresos que nutrieron la discusión en torno al tema educativo. Sin embargo, en este mismo tenor de reformulación de la enseñanza, se aprobó el reglamento de escuelas elementales un año antes de la Reforma, en 1883, el cual regulaba los planes de estudio, las condiciones de los preceptores y las circunstancias en las cuales los visitadores de escuela realizaban su trabajo. En definitiva, la Reforma Educativa de 1884 vino a cerrar un ciclo de incesantes búsquedas pedagógicas discutidas durante gran parte del siglo XIX y fue acompañada de la publicación del silabario de Claudio Matte: Nuevo método (fonético, analítico-sintético) para la enseñanza simultánea de la escritura y la lectura, propuesta pedagógica analítica-sintética que venía a romper y reestructurar la enseñanza silábica y repetitiva de las escuelas, y reflejaba en sus argumentos la crítica educativa que se venía realizando en Chile desde antes de la primera mitad del decimonónico:

Si en el primer año i en un ramo tan importante como el de lectura se emplea un método mecánico, que solo desarrolla la memoria, sin tomar para nada en cuenta la intelijencia i la observación, es difícil que este grave defecto se subsane más tarde en los otros ramos ${ }^{49}$.

47 Núñez citado en Latorre, La vida ejemplar, 25.

48 En Estados Unidos Horace Mann promovió una escuela común que daría a cada persona las destrezas necesarias para contribuir a la sociedad; esas destrezas fueron definidas por los dueños de la fábrica, los que decían qué era lo importante a enseñar (diseño del currículum). Orlando Retamal, "Una educación para reconciliar al hombre con la tierra. Solo la educación holística hará posible la continuidad de la vida", Estudios pedagógicos, n.o 24 (1998). http://dx.doi.org/10.4067/S0718-07051998000100009 (26 de septiembre de 2018).

49 Matte, Nuevo método, III. 
Por otro lado, el primer congreso pedagógico, realizado en Chile en 1889, marca un hito con respecto a este tema, llegando incluso a proponer prohibir el uso de didácticas monótonas y repetitivas, idea que se concretó una década después.

El Reglamento para el Régimen Interno de las Escuelas Primarias, dictado el 5 de abril de 1899, llegó a prohibir toda enseñanza basada en la memoria, señalando que esta debía ser "práctica e intuitiva, empezando por la observación de objetos sensibles para llegar después a la idea abstracta, a la comparación, a la generalización $i$ al raciocinio" ${ }^{\prime \prime}$.

En fin, el cierre del siglo XIX llegó acompañado de un decreto que vino a afianzar la postura crítica frente a las didácticas mecánicas, lo que llevaría a preguntarse qué ocurrió después, pues aún en el siglo XXI estas estrategias educativas son parte activa y fundamental de la cultura educativa chilena y no tan solo en la enseñanza primaria, sino de todos los niveles, desde el primer ciclo básico hasta la universidad.

\section{CONCLUSIÓN}

La independencia de Chile trajo consigo el inicio de profundos cambios estructurales en variadas materias, y específicamente en la educación se suscitó una reestructuración de su base: la educación religiosa. Las críticas fueron acompañadas por propuestas concretas y se sustentaron en argumentos tanto nacionales como internacionales. Uno de los puntos neurálgicos fue la enseñanza escolástica, la cual se entendía como una práctica repetitiva y monótona, herencia del colonialismo.

Para que esto se concretara era necesario justificar el porqué del cambio con evidencias claras, por lo tanto, desde el Estado, se ideó la estrategia de enviar a intelectuales nacionales y extranjeros a otras latitudes a conocer, comprender e imitar otros modelos educativos, los cuales tuvieran como sustento principal el aprendizaje comprensivo. En definitiva, se proponía la desacralización del modelo religioso imperante, sustentado en prácticas educativas repetitivas, que, según los promotores del cambio, no tenían como propósito la autonomía del individuo.

Por esta razón fueron tan importantes los teóricos en los cuales se inspiraron estas reformas, como Pestalozzi, Horace Mann y Herbart, entre otros, todos partidarios del uso de los sentidos en la educación, aunque los dos últimos también proponían que la educación debía ser una entidad tributaria a los intereses sociales y económicos de las sociedades, dicho de otro modo, la educación debía

50 Sol Serrano, Macarena Ponce y Francisca Rengifo, eds., "La educación nacional (1830-1930)", en Historia de la educación en Chile (1810-2010), tomo II (Santiago de Chile: Penguin Random House, 2013), 167. 
estar al servicio del crecimiento financiero del Estado. El modelo clerical ya no cumplía con este requisito.

Por último, a pesar de los intensos debates planteados a lo largo del siglo XIX e intensificados en la segunda mitad de esta época, lo curioso es que por casi todo este período, a pesar de las múltiples propuestas, se seguía debatiendo y evidenciando la misma necesidad detectada en los inicios de la independencia, lo cual indica que no tan solo hubo una continuidad en tratar de proponer cambios en la enseñanza-aprendizaje, sino también que las prácticas educativas asociadas a la repetición seguían vigentes a pesar de las constantes críticas, decretos, manuales y libros que se crearon para contrarrestarla. Al parecer, para el caso chileno, la disputa entre el conductismo y el constructivismo, pugna del siglo XX que tiene argumentos antagónicos similares, no tan solo en Chile, sino en el ámbito internacional, posee un debate semejante que lo antecedente, respecto a las estrategias de enseñanzas que se debían utilizar para el desarrollo cognitivo de los discentes.

\section{REFERENCIAS}

Amunátegui, Domingo. Los primeros años del Instituto Nacional 1813-1835. Santiago de Chile: Imprenta Cervantes, 1889.

Anales de la Universidad de Chile, tomo XX, correspondiente al primer semestre de 1862. Santiago de Chile: Imprenta del Ferrocarril, 1862.

Anguita, Ricardo. Leyes promulgadas en Chile desde 1810 hasta el 1..$^{\circ}$ de junio de 1913. Santiago de Chile: Imprenta, Litografía i Encuadernación Barcelona, 1913.

Campos, Fernando. Desarrollo educacional 1810-1960. Santiago de Chile: Editorial Andrés Bello, 1960.

Carbonell, Jaume. Pedagogías del siglo XX. Barcelona: Editorial CISSPRAXIS, 2000.

Carrillo, Paul. "Sistemas de memoria: reseña histórica, clasificación y conceptos actuales. Primera parte: Historia, taxonomía de la memoria, sistemas de memoria de largo plazo: la memoria semántica", Salud Mental, 33, n. ${ }^{\circ} 1$ (2010).

Conejeros, Juan. La influencia cultural francesa en la educación chilena, 1840 - 1880. Santiago de Chile: Universidad Católica Cardenal Raúl Silva Henríquez, 1999.

Cox, Cristián. “Política y políticas educacionales en Chile 1990-2010". Revista Uruguaya de Ciencia Política 21, n. ${ }^{\circ} 1$ (2012): 25.

Danziger, Kurt. Does memory have a history? En Marking the Mind a History of Memory, New York: Cambridge University Press, 2008. "La memoria, ¿tiene una historia?". Traducción de Hernán Scholten y Sebastián Benítez. Cátedra I de Historia de la Psicología. Buenos Aires: Facultad de Psicología, UBA, 2012.

González, Guillermo. Memoria histórica de la Educación Pública en Chile, 1810-1900. Santiago de Chile: Imprenta de Meza Hermanos, 1913.

Klafki, Wolfgang. “La importancia de las teorías clásicas de la educación para una concepción de la educación general hoy". Revista de Educación, n.o 291 (1990): 105-127.

Labarca, Amanda. Historia de la enseñanza en Chile. Santiago de Chile: Imprenta Universitaria, 1939.

Lara, Jesús. "La influencia dominica en la Universidad Real de San Felipe y el traspaso a un modelo borbónico de educación". En Saberes y poder. Colegios y universidades durante el reformismo borbónico, edición de Benito Moya. Córdoba: Ediciones Universidad Católica de Córdoba, 2015.

Lara, Jesús. “Aproximación histórica-educativa al primer sistema de evaluación usado en Chile: los exámenes para acceder el grado de bachiller, licenciado, maestro y doctor en Teología en la Universidad Pontificia Santo Tomás de Aquino". Cuadernos Chilenos de Historia de la 
Educación, n. ${ }^{\circ} 9$ (2018): 52-80.

Latorre, Gonzalo. La vida ejemplar de José Abelardo Núñez Murúa 1840-1910. Santiago de Chile: Escuela Nacional de Artes Gráficas, 1944.

Mantovani, Juan. Juan Enrique Pestalozzi. Guatemala: Universidad San Carlos de Guatemala, 1946.

Matte, Claudio. Nuevo método (fonético, analítico-sintético) para la enseñanza simultánea de la escritura y la lectura. Leipzig: Imprenta de F. A. Brockhaus, 1884.

Medina, José. Historia de la Real Universidad de San Felipe de Santiago de Chile. Santiago de Chile: Imprenta y Litografía Universo, 1928.

Muñoz, José. Historia elemental de la pedagojía chilena. Santiago de Chile: Sociedad Imprenta y Litografía Universo, 1918.

Narváez, Eleázar. “Una mirada a la escuela nueva”. Educere 10, n. 35 (2006).

Núñez, José A. Consejos sobre educación, tomados de M. Th. H. Barrau. Santiago de Chile: Imprenta Nacional, 1868.

Núñez, José A. Estudios sobre educación moderna. Organización de Escuelas Normales. Santiago de Chile: Imprenta de la Librería Americana, 1883.

Ortiz, Alexander. "Configuración epistémica de la pedagogía. Tendencias que han proliferado en la historia de la educación". Revista historia de la educación latinoamericana, 19, n. 24 (2017).

Pérez, Ramón. El currículum y sus componentes. Hacia un modelo integrador. Barcelona: Oikos-Tau, 1994.

Pestalozzi, Juan Enrique. Cómo Gertrudis enseña a sus hijos. Traducido por José Tadeo Sepúlveda. Coatepec: Tipografía de Antonio M. Rebolledo, 1889.

Pita, Roger. "Fundar escuelas para consolidar la República y formar ciudadanos. Una aproximación para el caso colombiano". Revista historia de la educación latinoamericana, 17, n. ${ }^{\circ} 25$ (2015).

Pradenas, Luis. Teatro en Chile. Huellas y trayectorias. Siglos XVI- XX. Santiago de Chile: LOM, 2006.

Rossig, Eduardo. Manual de práctica escolar. Santiago de Chile: Imprenta Roma, 1896.

Retamal, Orlando. "Una educación para reconciliar al hombre con la tierra. Solo la educación holística hará posible la continuidad de la vida". Estudios pedagógicos, n. ${ }^{\circ} 24$ (1998) http://dx.doi. org/10.4067/S0718-07051998000100009 (29/9/2018).

Serrano, Sol. Universidad y nación. Chile en el siglo XIX. Santiago de Chile: Editorial Universitaria, 1994.

Serrano, Sol, Macarena Ponce y Francisca Rengifo (editoras). "La educación nacional (1830-1930)". En Historia de la educación en Chile (1810-2010). Tomo II. Santiago de Chile: Penguin Random House, 2013.

\section{Cómo citar:}

Lara Coronado, Jesús. “Crítica al uso de la memoria como recurso de aprendizaje durante el siglo XIX en Chile". Revista Historia de la Educación Latinoamericana. Vol. 21 No. 33 (2019): 87-106

https:https://doi.org/10.19053/01227238.9097

(c) (i) @) Es Esta obra está bajo una licencia Creative Commons. Reconocimiento-No Comercial-Sin Obra Derivada 2.5 Colombia. 